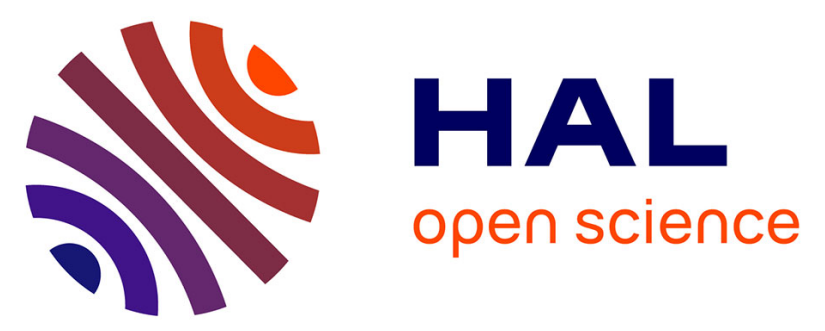

\title{
CD146 deficiency promotes plaque formation in a mouse model of atherosclerosis by enhancing RANTES secretion and leukocyte recruitment
}

Muriel Blin, Richard Bachelier, Karim Fallague, Karima Moussouni, Michel Aurrand-Lions, Samantha Fernandez, Benjamin Guillet, Stéphane Robert, Alexandrine Foucault-Bertaud, Nathalie Bardin, et al.

\section{To cite this version:}

Muriel Blin, Richard Bachelier, Karim Fallague, Karima Moussouni, Michel Aurrand-Lions, et al.. CD146 deficiency promotes plaque formation in a mouse model of atherosclerosis by enhancing RANTES secretion and leukocyte recruitment. Journal of Molecular and Cellular Cardiology, 2019, 130, pp.76-87. 10.1016/j.yjmcc.2019.03.017 . hal-02511513

\section{HAL Id: hal-02511513 \\ https://hal.science/hal-02511513}

Submitted on 26 May 2020

HAL is a multi-disciplinary open access archive for the deposit and dissemination of scientific research documents, whether they are published or not. The documents may come from teaching and research institutions in France or abroad, or from public or private research centers.
L'archive ouverte pluridisciplinaire HAL, est destinée au dépôt et à la diffusion de documents scientifiques de niveau recherche, publiés ou non, émanant des établissements d'enseignement et de recherche français ou étrangers, des laboratoires publics ou privés. 


\section{Accepted Manuscript}

CD146 deficiency promotes plaque formation in a mouse model of atherosclerosis by enhancing RANTES secretion and leukocyte recruitment

MurielG. Blin, Richard Bachelier, Karim Fallague, Karima Moussouni, Michel Aurrand-Lions, Samantha Fernandez, Benjamin Guillet, Stéphane Robert, Alexandrine Foucault-

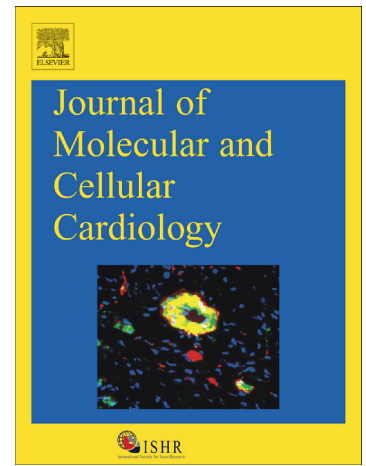
Bertaud, Nathalie Bardin, Marcel Blot-Chabaud, Françoise Dignat-George, Aurélie S. Leroyer

PII: S0022-2828(18)30900-3

DOI: https://doi.org/10.1016/j.yjmcc.2019.03.017

Reference: YJMCC 8948

To appear in: Journal of Molecular and Cellular Cardiology

Received date: 6 September 2018

Revised date: 26 February 2019

Accepted date: 25 March 2019

Please cite this article as: M. Blin, R. Bachelier, K. Fallague, et al., CD146 deficiency promotes plaque formation in a mouse model of atherosclerosis by enhancing RANTES secretion and leukocyte recruitment, Journal of Molecular and Cellular Cardiology, https://doi.org/10.1016/j.yjmcc.2019.03.017

This is a PDF file of an unedited manuscript that has been accepted for publication. As a service to our customers we are providing this early version of the manuscript. The manuscript will undergo copyediting, typesetting, and review of the resulting proof before it is published in its final form. Please note that during the production process errors may be discovered which could affect the content, and all legal disclaimers that apply to the journal pertain. 
CD146 deficiency promotes plaque formation in a mouse model of atherosclerosis by enhancing RANTES secretion and leukocyte recruitment

Muriel G. Blin ${ }^{1}$, Richard Bachelier ${ }^{1}$, Karim Fallague ${ }^{1}$, Karima Moussouni ${ }^{1}$, Michel AurrandLions $^{2}$, Samantha Fernandez ${ }^{3}$, Benjamin Guillet ${ }^{1,3,4}$, Stéphane Robert ${ }^{1}$, Alexandrine Foucault-Bertaud $^{1}$, Nathalie Bardin ${ }^{1,5}$, Marcel Blot-Chabaud ${ }^{1}$, Françoise Dignat-George ${ }^{1,5}$ and Aurélie S. Leroyer ${ }^{1}$.

${ }^{1}$ Aix-Marseille Univ., INSERM, INRA, C2VN, Marseille, France

${ }^{2}$ Aix Marseille Univ., CNRS, INSERM, Institut Paoli-Calmettes, CRCM, Marseille, France

${ }^{3}$ Aix-Marseille Univ., CERIMED, Secteur Nucléaire Pré-clinique, Timone, 13005 Marseille, France

${ }^{4}$ Assistance Publique-Hôpitaux de Marseille, Hôpital Nord, Marseille, France

${ }^{5}$ Assistance Publique-Hôpitaux de Marseille, Hôpital de la Conception, 13385 Marseille, France

\section{Correspondence:}

Aurélie S. Leroyer

Aix-Marseille University

INSERM, INRA, C2VN

27 bd Jean Moulin

13385 Marseille

FRANCE

Fax 334.9183.5602

Tel 334.9183.5687

aurelie.leroyer@univ-amu.fr 


\section{Abstract}

Aims: The progression of atherosclerosis is based on the continued recruitment of leukocytes in the vessel wall. The previously described role of CD146 in leukocyte infiltration suggests an involvement for this adhesion molecule in the inflammatory response. In this study, we investigated the role of CD146 in leukocyte recruitment by using an experimental models of atherogenesis.

Methods and Results: The role of CD146 was explored in atherosclerosis by crossing CD146-/- mice with ApoE-/- mice. CD146 -/-/ApoE -/- and ApoE -/- mice were fed a Western diet for 24 weeks and were monitored for aortic wall thickness using high frequency ultrasound. The arterial wall was significantly thicker in CD146-deficient mice. After 24 weeks of Western diet, a significant increase of atheroma in both total aortic lesion and aortic sinus of CD146-null mice was observed. In addition, atherosclerotic lesions were more inflammatory since plaques from CD146-deficient mice contained more neutrophils and macrophages. This was due to up-regulation of RANTES secretion by macrophages in CD146-deficient atherosclerotic arteries. This prompted us to further address the function of CD146 in leukocyte recruitment during acute inflammation by using a second experimental model of peritonitis induce by thioglycollate. Neutrophil recruitment was significantly increased in CD146-deficient mice 12 hours after peritonitis induction and associated with higher RANTES levels in the peritoneal cavity. In CD146-null macrophages, we also showed that increased RANTES production was dependent on constitutive inhibition of the p38MAPK signaling pathway in CD146-null macrophages. Finally, Maraviroc, a RANTES receptor antagonist, was able to reduce atherosclerotic lesions and neutrophilia in CD146deficient mice to the same level as that found in ApoE -/- mice.

Conclusions: Our data indicate that CD146 deficiency is associated with the upregulation of RANTES production and increased inflammation of atheroma, which could influence the atherosclerotic plaque fate. Thus, these data identify CD146 agonists as potential new therapeutic candidates for atherosclerosis treatment. 


\section{Introduction}

CD146 is an adhesion molecule detected on all endothelial cells of the vascular tree, regardless of the vessel caliber or anatomical region ${ }^{1,2}$. It was first discovered in 1987 and named MCAM (Melanoma Cell Adhesion Molecule) since it was first identified as a glycoprotein with a molecular weight of $113 \mathrm{kDa}$ at the membrane of human melanoma ${ }^{3}$. CD146 is also described on other cell types such as smooth muscle cells, pericytes, cancer cells, subpopulations of lymphocytes and also intraplaque macrophages ${ }^{3-7}$. We have previously shown that CD146 plays a role in the control of vascular integrity and notably cell cohesion and permeability ${ }^{8}$. We identified the molecular pathways regulated by CD146 in endothelial cells by showing that cross-linking of CD146 triggered tyrosine phosphorylation of non-receptor tyrosine kinase p59fyn, FAK and paxillin ${ }^{9,10}$. CD146 was also found to activate the AKT/p38 and MAPKs/NF-kB pathways ${ }^{11}$. More recently, CD146 has been reported to interact with VEGFR-2 and to contribute to VEGF-dependent activation of VEGFR-2 ${ }^{12}$. Interestingly, numerous studies are in favor of a role of CD146 in the regulation of the inflammatory response. Indeed, its expression and localization in endothelial cells are regulated in response to stimulation with $\mathrm{TNF}^{13}$. Furthermore, CD146 and its soluble form (sCD146) promote the transmigration of monocytes in vitro ${ }^{13}$. Several studies conducted in vitro demonstrated the involvement of CD146 in the first steps of lymphocyte rolling on the endothelium ${ }^{14-16}$. In addition, CD146 has been shown to regulate cytokine release from macrophages in a model of lung bacterial infection ${ }^{17}$. The expression levels of CD146/sCD146 increase in several inflammatory diseases and pathologies associated with endothelial lesion ${ }^{16,18-24}$. Interestingly, CD146 transcripts and proteins have been found upregulated in human atherosclerotic plaque biopsies $^{6,}{ }^{25}$, notably on intraplaque macrophages. A recent study reported that CD146 controls the formation of macrophage foam cells and their retention within the plaque during atherosclerosis exacerbation ${ }^{7}$. Atherosclerosis is a chronic inflammatory disease of the great vessels. Atheromatous 
disease clinically manifests by the onset of acute ischemic stroke or myocardial infarction following the rupture or erosion of atherosclerotic plaque that makes this disease one of the main causes of death worldwide. Thus, preventing atherosclerosis is one of the essential issues of contemporary cardiology and understanding its fundamental mechanisms, although challenging, is required for the development of new therapeutic strategies. The evolution of the disease is based in part on the continued recruitment of leukocytes in the inflammatory vessel wall ${ }^{26-28}$. Indeed, the fatty streak, already present in young children, is an inflammatory lesion consisting of macrophages accumulated in response to lipid entry in the vessel wall.

The well-described role of CD146 in leukocyte infiltration in vitro suggests a role of this molecule in the early stages of atherosclerotic plaque formation. In this study, we investigate the involvement of CD146 in leukocyte recruitment in vivo, using different experimental models.

\section{Methods}

\section{Animals}

CD146-floxed and CD146-KO mice were generated as previously described and backcrossed for more than 10 generations on the C57BL/6J background ${ }^{6}$. CD146-floxed mice were first crossed with the B6.Cg-Gt(ROSA)26Sortm6(CAG-ZsGreen1)Hze/J mice (Jackson Laboratory), which express the fluorescent protein ZsGreen1 as a reporter for CRE-recombinase activity. Then, mice with endothelial cell-specific deletion of the CD146 gene (CD146 EC-KO mice) were generated by further crossing CD146 flox-Zs Green animals with the Cdh5 (PAC)-CreERT2 mouse strain established by Ralf Adams. These endothelial CD146 KO mice were further backcrossed for more than 10 generations on the C57BL/6J background. The deletion of the CD146 gene was induced by I.P. injections of tamoxifen diluted in corn oil (10 mg/ml solution, $1 \mathrm{mg}$ tamoxifen/injection) and administered on 3 consecutive days. Primers for genotyping CD146 alleles were 5'- 
TCACTTGACAGTGTGATGGT-3' (forward primer used to detect CD146 WT, floxed and KO alleles), 5'-CCTTAGAAAGCAGGGATTCA-3' (reverse primer used to detect CD146 WT and floxed alleles) and 5'-CCCAAATCCTCTGGAAGACA-3' (reverse primer used to detect CD146 KO allele). Chimeric mice were obtained after transfer of $1.10^{6}$ cells of WT bonemarrow in CD146 -/- mice after 800 rad of irradiation. CD146-deficient mice were crossed with ApoE -/- mice (C57BL/6J background, Janvier Labs) and backcrossed for more than 10 generations on the C57BL/6J background. Only male mice were analyzed in this study. Genotyping was carried out with primers for the wild-type and deleted ApoE alleles 5'GCCTAGCCGAGGGAGAGCCG-3' (olMR0180), 5'-TGTGACTTGGGAGCTCTGCAGC -3' (olMR0181) and 5'-GCCGCCCCGACTGCATCT-3' (oIMR0182) (as recommended by the Jackson Laboratory). Animals were fed a Western diet (20\% fat, 0.2\% cholesterol) for 24 weeks beginning at 7 weeks of age. Maraviroc treatment $(50 \mathrm{mg} / \mathrm{kg}$ by gavage) was administered daily between 12 and 24 weeks of Western diet and corn oil vehicle was used as control. Mice were anesthetized with $3 \%$ sevoflurane in oxygen and intracardially perfused with PBS before being euthanized by cervical dislocation. All animal care and experiments were performed as recommended by the European Community Guidelines (directive 2010/63/UE) and approved by the Marseille Ethical Committee (approval 00781.02).

\section{Peritonitis model}

Peritonitis was induced by intraperitoneal (IP) injection of a $3 \%$ thioglycollate sterile solution (Sigma). Leukocytes were harvested by flushing cells from peritoneal cavity with 3 lavages of a $10 \mathrm{ml}$ cold PBS-1.25mM EDTA sterile solution 12 hour post-injection.

\section{Flow cytometry analysis of leukocyte subpopulations}

Leukocyte subpopulations from blood were analyzed by flow cytometry (Gallios, Beckman Coulter). Monocytes and neutrophils were identified with the following mix of antibodies: FITC-conjugated anti-Ly6c (Becton Dickinson, 561085), phycoerythrin (PE)-conjugated antiF4/80 (eBioscience, 12480180), PE-conjugated cyanine 5.5 (PerCP-Cy5.5)-anti-Ly6G 
(eBioscience, 45593180), PE- cyanine 7-conjugated anti-CD11c (eBioscience, 25011481), phycocyanin (APC)-conjugated anti-CD11b (eBioscience, 17011281) and efluor 780conjugated anti-CD45 (eBioscience, 47045180). Lymphocytes were identified with the following mix of antibodies: FITC-conjugated anti-Ly6G (Gr-1) (eBioscience, 11593181), phycoerythrin (PE)-conjugated anti-F4/80 (eBioscience, 12480180), PE-conjugated cyanine 5.5 (PerCP-Cy5.5)-anti-CD3 (eBioscience, 45003182), PE- cyanine 7-conjugated anti-B220 (eBioscience, 25045281), allophycocyanin (APC)-conjugated anti-CD11b (eBioscience, 17011281) and eFluor 780-conjugated anti-CD45 (eBioscience, 47045180).

\section{Measure of aortic wall thickness}

The mice were anesthetized with $3 \%$ sevoflurane in oxygen and maintained on a heated stage throughout the ultrasound imaging sessions. Ultrasound imaging was performed using a dedicated small animal ultrasound imager with MS 550 probe (Vevo 2100; VisualSonics; Canada). The aortic intima media thickness was assessed by a high-resolution M-mode ultrasonography of the aortic arch. Image data sets were analyzed with Vevo2100 software. All measurements were performed in a blind way.

\section{Extent of atherosclerotic lesions}

Whole aortae were removed, fixed in $4 \%$ paraformaldehyde and were longitudinally incised. Whole aortae were stained with Oil Red O, slides were counterstained with hematoxylin, and examined under a light microscope (Leica, DMI8, 5X objective). The hearts were taken out, fixed in $4 \%$ paraformaldehyde for 2 hours, and placed in a 30\% PBS sucrose solution overnight at $4^{\circ} \mathrm{C}$ before being included in OCT cutting medium and frozen at $-80^{\circ} \mathrm{C}$. Serial 8 $\mu \mathrm{m}$ transversal sections of aortic sinus were stained with Oil Red O, counterstained with hematoxylin, and examined under a light microscope (10X). Both the en face lesion and aortic sinus area were measured morphometrically using National Institutes of Health $(\mathrm{NIH})$ ImageJ Version 1.45 software. Lesion quantification was analyzed on 3 different sections and expressed as the area of positive immunostaining. All measurements were performed in 
a double-blind way.

\section{Composition of atherosclerotic lesions}

Serial $8-\mu \mathrm{m}$ transversal cryo-sections of aortic sinus were obtained. Plaque composition was determined with the use of monoclonal antibodies directed against specific epitopes of macrophages (clone MOMA-2, Millipore, MAB1852), neutrophils (anti-Ly6G-FITC, eBioscience, 47045180), neutrophil elastase (Abcam, ab21595) and RANTES protein (clone C19, Santa Cruz, sc-1410). For detection, goat anti-mouse horseradish peroxidase (HRP), goat anti-rabbit HRP, goat anti-rat HRP, rabbit anti-goat FITC, donkey anti-goat alexa 546 and goat anti-rat alexa 647 conjugated secondary antibodies were used (Thermo Fisher Scientific). Plaques stained with secondary antibodies only were used as controls of nonspecific staining. Slides were examined under a light microscope. Isolectin GS-IB4AlexaFluor488 was also used (thermofisher). NIH ImageJ Version 1.45 software was used for quantification. All measurements were performed in a double-blind way.

\section{Bone-marrow derived myeloid cell isolation and culture}

Femora and tibiae were retrieved and the bone marrow was flushed out with chilled PBS using a 25G needle. The cells were washed and resuspended in RPMl culture medium (RPMl 1640 with $10 \%$ fetal bovine serum, 100U/ml Penicillin, $100 \mathrm{ug} / \mathrm{ml}$ streptomycin, $200 \mathrm{mM} \mathrm{L-glutamine)} \mathrm{in} \mathrm{a} \mathrm{T25} \mathrm{culture} \mathrm{flask} \mathrm{and} \mathrm{kept} \mathrm{for} 2$ days at $37^{\circ} \mathrm{C}, 5 \%$ CO2 and 95\% humidity. Non-adherent bone marrow cells were further collected, washed once and resuspended in RPMI culture medium supplemented with $20 \%$ L929 supernatant completed medium. An inhibitor of NF-KB (Bay 11-7082) was added to the medium at the concentration of $10 \mathrm{mM}$ for 3 hours. Inhibitors of VEGFR-2 (Sunitinib, $1 \mu \mathrm{M}$ ) and p38-MAPK (SB203580, $1 \mu \mathrm{M})$ were added for 24 hours.

\section{RANTES quantification in plasma and supernatant}


Plasma was prepared by centrifugation of blood samples collected in EDTA tubes. Supernatant of cultured bone-marrow derived myeloid cells were collected and centrifuged. RANTES ELISA was performed using a commercially available kit according to manufacturer's instructions (eBioscience, BMS6009INST, sensitivity $1.2 \mathrm{pg} / \mathrm{ml}$ ).

\section{Determination of plasma lipid levels}

Blood samples were collected in EDTA tubes by intracardiac puncture after overnight fasting. Plasma was separated by centrifugation and analyzed for total cholesterol levels using enzymatic colorimetric assays according to the manufacturer's instructions (bioMerieux, France).

\section{Western blot analyses}

Cultured bone-marrow derived macrophages were lysed in RIPA buffer containing protease/phosphatase inhibitors (Thermo Fisher Scientific 88666 and 88667). Equal amounts of proteins were resolved by SDS-PAGE, and then immunoblotted using anti-phospho-NF-KB p65 (ser536), anti-NF-kB p65, anti-IKKB, anti-phospho-IKKa/ß (ser 176/180), anti-phosphoVEGFR2 (Tyr 1054/Tyr 1059), anti-VEGFR2, anti-phospho-p38 MAPK (Thr180/Tyr182) and anti-p38 MAPK antibodies. All the antibodies were from Cell Signaling except anti-phosphoVEGFR2 (Abcam).

\section{PCR array of atherosclerotic lesions}

Total RNAs from abdominal aortae were purified using TRlzol reagent (Life technologies, 15596026) and reverse transcribed (Takara kit, Clontech, RR037A). The evaluation of inflammatory gene expression profiles was carried out with $\mathrm{RT}^{2}$ Profiler $^{\mathrm{TM}} \mathrm{PCR}$ Array (Mouse Atherosclerosis PCR array, SABiosciences product, Qiagen).

\section{Statistical analysis}

The data are expressed as the mean \pm SEM. Student's t-tests and Mann Whitney tests were 
used for independent samples. Correlations were evaluated using Spearman correlation coefficients. Statistical analyses were performed using Prism software (GraphPad Software, USA). The differences were considered significant at $p<0.05$.

\section{Results}

CD146 deficiency promotes atherosclerotic plaque inflammation and accelerated atherosclerosis in mice

We first examined whether CD146 could influence atherogenesis. To this aim, CD146 -/mice were bred with ApoE -/- mice and fed with Western diet for 24 weeks. Aortic wall thickness was monitored using high frequency ultrasound. From 12 to 24 weeks, we observed a trend to accelerated atherosclerosis in CD146 -/-/ApoE -/- compared to ApoE-/mice. However, there were no significant differences 12 weeks after Western diet in both arterial wall thickness and atherosclerotic lesion extent (Supplemental Figure 1A). After 24 weeks of Western diet, the arterial wall thickness was significantly higher in CD146-deficient mice $(0.27 \pm 0.01 \mathrm{~mm}$ vs $0.19 \pm 0.01 \mathrm{~mm} ; \mathrm{p}=0.012)$ (Supplemental Figure $1 \mathrm{~B}$ ) although weights and total cholesterol plasma levels were similar between the two groups of mice (Supplemental Figure 1C). Next, we evaluated the extent of atherosclerosis in aortae by Oil Red $\mathrm{O}$ staining and measured the staining on en face sections. CD146 -/-/ ApoE -/- mice displayed significantly larger lesion areas in the total aorta when compared to ApoE -/- mice ( $45 \%$ vs $33 \%$ of total aorta, $p=0.004$ ) (Figure $1 \mathrm{~A}$ ). We analyzed the thickness of the media, and adventitia on aortic sinus sections thanks to hematoxillin and eosin staining and we did not observe any difference between the two groups of mice, indicating that atherosclerotic plaque was effectively responsible of the increase for arterial wall thickness. In addition, microscopic analysis of lesions stained with Oil red $\mathrm{O}$ at the level of the aortic sinus also revealed significantly larger atherosclerotic lesions in CD146-null mice $(p=0.001)$ (Figure 1B). 
We further analyzed the inflammatory content of atherosclerotic lesions by quantification of macrophage and neutrophil infiltrations using immunohistochemistry. Atherosclerotic plaques from CD146-deficient animals contained significantly more MOMA-2-positive macrophages in comparison to ApoE -/- plaques $(46.8 \pm 2.9 \%$ of plaque vs $31.1 \pm 4.6 \%, n=10$ each group, $\mathrm{p}=0.029$ ) (Figure 1C). We evaluated the neutrophil content in aortic root plaques by immunostaining with an antibody directed against Ly6G and observed that it was significantly increased in CD146 -/-/ApoE -/- animals $(2.5 \pm 0.5 \%$ of plaque vs $0.7 \pm 0.3 \%, n=6$ each group, $\mathrm{p}=0.032$ ) (Figure 1D). In addition, our data suggest that neutrophils and macrophages were active within atherosclerotic lesions as evidenced by a significant increase of neutrophil elastase (NE) staining in the aortic sinus in the absence of CD146 $(32.6 \pm 7.6 \%$ of plaque vs $15.5 \pm 2.3 \%, n=6$ each group, $p=0.032$ ) (Figure $1 E$ ).

These results demonstrate that the atherosclerotic lesions in CD146 -/-/ApoE -/- mice were not only larger but also more inflammatory than in ApoE -/- mice.

\section{CD146 deficiency leads to neutrophilia and upregulation of CCL5/RANTES during atherosclerosis}

We further investigated whether CD146 could influence atherosclerotic plaque fate by evaluating the inflammatory response in CD146-deficient mice during atherogenesis. First, we determined the circulating leukocyte subpopulations after 24 weeks of Western diet using flow cytometry analysis (Supplemental Figure 2). Circulating neutrophils were significantly increased in the absence of CD146 (Figure 2A, $n=6$ each group, $p=0.002$ ), whereas circulating monocytes remained unchanged, whether Ly6C low or high monocytes (Figure 2B). Because we observed a marked increase of neutrophil/macrophage content within atherosclerotic lesions (Figures 1C and 1D), correlated with neutrophilia when CD146 was absent, we next studied the mechanisms of inflammatory cell accumulation. We analyzed the levels of circulating cytokines using ELISA and observed a significant 2-fold increase of plasmatic RANTES during atherosclerosis only in CD146-/- ApoE-/- animals ( $n=6$ each group, $\mathrm{p}=0.02$ ) (Figure $2 \mathrm{C}$ ) whereas we did not detect any significant change of plasmatic 
CCL2, IFN- - , TNF $\alpha$ and IL-6 in CD146 -/-/ApoE -/- mice (Supplemental Figure 1D). Circulating RANTES was not increased in non-atherosclerotic mice (Supplemental Figure 3A). Interestingly, we analyzed the correlation between plasmatic RANTES levels and neutrophil accumulation in atherosclerotic plaques and found a significant positive correlation both from ApoE -/- CD146 -/- and ApoE -/- animals. (Figure 2D), suggesting that circulating RANTES was associated with the neutrophil recruitment within atheroma. Moreover, PCR array analysis performed on mRNA extracted from atherosclerotic aortae showed an increase of CCL5/RANTES gene expression in CD146 -/-/ApoE -/- mice compared to ApoE /- aortae ( $n=3$ for each group, Supplemental Figure 3B). We further evaluated the RANTES content in aortic root plaques by immunostaining and showed that it was 2 -fold increased in CD146 -/-/ApoE -/- animals (Figure 2E).

Our results show that CD146 deficiency promotes neutrophilia during atherosclerosis and that CD146 deficiency was associated with increased levels of both plaque and plasmatic RANTES. These results suggest an important role for RANTES in the recruitment of neutrophils and monocytes into CD146-deficient atherosclerotic arteries.

\section{CD146 deficiency leads to increased neutrophil recruitment and RANTES secretion during thioglycollate-induced peritonitis}

Since RANTES is a chemokine involved in neutrophil recruitment, we next examined whether CD146 could influence this process. First, using flow cytometry, we quantified numbers of circulating leukocytes at the basal state in WT and CD146-deficient mice. We did not observe any difference in Ly6G+ circulating neutrophils, Ly6C+ circulating monocytes, CD3+ or B220+ circulating lymphocytes in CD146-null animals in comparison to WT (Supplemental Figure 4A). We next investigated whether CD146 could impact leukocyte recruitment in a model of acute inflammation. Thus, we induced peritonitis by IP injection of thioglycollate and analyzed the chemokine-dependent recruitment of all leukocyte sub-populations 12 hours after injection ${ }^{29}$. The distribution of leukocyte subpopulations in blood was similar in WT and CD146-KO mice (Supplemental Figure 4B). However, we found a significant increase only 
for neutrophils recruited within the peritoneal cavity in CD146-deficient animals as compared to control (Supplemental Figure 4C). We further examined the relative contribution of CD146 from endothelial cells and leukocytes on neutrophil recruitment. To that aim, we replicated the model of thioglycollate-induced peritonitis in endothelial specific CD146 deficient mice $\left(\mathrm{CD} 146^{\mathrm{EC}-\mathrm{KO}}\right)$ and in chimeric mice obtained by WT bone-marrow transfer in CD146 KO mice. Interestingly, we demonstrated that neutrophil recruitment was significantly rescued in both $\mathrm{CD} 146^{\mathrm{EC}-\mathrm{KO}}$ and chimeric mice (Supplemental Figure 4C). Furthermore, we analyzed the levels of RANTES in the peritoneal cavity and found higher levels of RANTES in the peritoneal fluid of CD146-null peritonitis-induced animals in comparison to that of WT mice (Supplemental Figure 4C) whereas RANTES levels were similar to those of WT animals in both $\mathrm{CD} 146^{\mathrm{EC}-\mathrm{KO}}$ and chimeric mice.

Our results indicate that constitutive CD146 deficiency leads to increased neutrophil recruitment, which is independent of endothelial CD146 but may involve CD146 harbored by leukocytes and that this process could be mediated by RANTES.

\section{CD146-mediated RANTES regulation is dependent on p38-MAPK macrophage} activation

RANTES is mainly released by macrophages and platelets during atherosclerosis. Platelet levels were not different in the absence of CD146 (data not shown). However, multiple factors may regulate RANTES release such as the actions of IFN- $\gamma$, TNF- $\alpha$ and II- 6 but we did not observe any differences between ApoE -/- and ApoE -/-/CD146 -/- mice (Supplemental Figure 1D).

Interestingly, we observed that plasma levels of RANTES were correlated with the percentage of accumulated macrophages within atheroma, and that a certain degree of colocalization between plaque RANTES and MOMA-positive macrophages could be observed in aortic root plaques (Figure $2 \mathrm{~F}$ ). However, we could not rule out the possibility that there were other sources of RANTES within atheroma, like endothelial cells, since we also observed RANTES co-localization with isolectin (Supplemental Figure 3C). Nonetheless, in 
line with previous findings ${ }^{30,31}$, RANTES was mainly observed inside the atheroma, closed to macrophages.

To further elucidate the mechanisms of RANTES regulation, we isolated bone-marrow derived macrophages (BMDM) from ApoE -/- and CD146 -/-/ApoE -/- mice. We first quantified RANTES secretion in BMDM supernatant after 7 days of culture. Interestingly, CD146-deficient macrophages produced significantly higher levels of RANTES as compared to cells harboring CD146 not only during atherosclerosis (ApoE -/- vs. CD146 -/-/ApoE -/mice, $n=4$ each group, $p=0.026$, Figure $3 A$ ) but also in non-atherosclerotic animals (WT vs. CD146 KO mice, Supplemental Figure 3D). Because analysis of the mouse RANTES promoter region identified a NF-kB transcription factor-binding $\operatorname{site}^{32}$, we further analyzed whether CD146 deficiency could influence the regulation of RANTES secretion through NFKB pathway. ApoE -/- and CD146 -/-/ApoE -/- macrophages were cultured in the presence or absence of the selective NF-KB inhibitor Bay 11-7082. We did not detect any difference in NF-KB and IKKß phosphorylation between the two groups of cells cultured without inhibitor (Supplemental Figure 5A). In addition, although the inhibitor was efficient on cells as evidenced by a decrease of NF-KB phosphorylation, the CD146-mediated secretion of RANTES was not affected when NF-KB pathway was impaired and CD146-deficient cells still produced significantly higher levels of RANTES than CD146-expressing cells in the presence of NF-kB inhibitor (Supplemental Figure 5B). We thus investigated alternative pathways controlling RANTES expression and found a significant decrease of p38-MAPK phosphorylation in CD146-deficient cells ( $n=4$ each group, $p=0.029$, Figure 3B). Since CD146 was previously described to be involved in VEGFR-2 activation, and because p38MAPK phosphorylation could be a consequence of VEGFR-2 activation, we also explored the VEGFR-2 signaling in ApoE -/- and CD146 -/-/ApoE -/- myeloid cells. VEGFR-2 phosphorylation was significantly decreased in absence of CD146 expression ( $n=4$ each group, $p=0.029$, Figure 3B). Finally, we analyzed RANTES secretion by bone-marrow derived macrophages exposed to sunitinib or SB203580 in order to block the VEGFR-2 or p38-MAPK signaling pathways respectively. Interestingly, we observed that addition of these 
inhibitors significantly increased the RANTES secretion from CD146-positive macrophages at the same level as that of CD146-null macrophages ( $n=4$ each group, Figure $3 C$ ). In order to investigate if these pathways were also impaired in vivo, we performed a p38 staining of aortic sinus and we observed a significant decrease of p38 phosphorylation in CD146 deficient atherosclerotic plaques (Figure 3D).

Altogether, these results indicate that CD146 downregulated RANTES production by macrophages through the activation of VEGFR-2 and p38-MAPK pathways (Supplemental Figure 6).

\section{RANTES receptor antagonist Maraviroc abolishes the increased neutrophil} recruitment during atherosclerosis and decreases plaque size in CD146 -/-/ ApoE -/mice

We next investigated whether RANTES was responsible for both neutrophilia and accelerated atherosclerosis in CD146-deficient mice. To this end, we inhibited RANTES interaction with its receptor using Maraviroc, a RANTES receptor antagonist. Mice were daily treated with Maraviroc from 12 to 24 weeks of Western diet. After 12 weeks of RANTES receptor inhibition, we observed a significant decrease of atherosclerotic lesions on whole aorta (Figure 4A) and on aortic sinus in CD146 -/-/ApoE -/- mice (Figure 4B). Next, we analyzed the neutrophil infiltration within the atherosclerotic plaque using Ly6G immunostaining. Neutrophil content in CD146 -/-/ApoE -/- mice was significantly reduced to the same level as that observed in ApoE-/- mice (Figure 4C). This was associated with a significant decrease of circulating neutrophils, as evidenced by flow cytometry, observed in plasma from ApoE-/- and CD146 -/-/ApoE -/- mice treated with Maraviroc (Figure 4D).

Overall, we demonstrated that RANTES signaling inhibition abolishes the accelerated atherosclerosis observed in CD146 -/-/ApoE -/- mice by reducing neutrophil recruitment in plasma and plaque. 


\section{Discussion}

In the present study, we show for the first time that CD146 deficiency leads to an increased RANTES secretion by macrophages, promoting neutrophilia and neutrophil accumulation at sites of inflammation such as atherosclerotic plaque. This was confirmed in another model of inflammation of the peritoneal cavity.

Very few studies have investigated the role of CD146 in atherosclerosis. It was previously proposed that the soluble form of CD146 could be a biomarker of subclinical atherosclerosis since levels of SCD146 correlated with carotid atherosclerosis in patients, which could be the hallmark of the membrane part decrease ${ }^{6,25}$. Although CD146 was overexpressed within human atherosclerotic lesions ${ }^{6,25}$, only one study has focused on the role of CD146 in the development of atherosclerotic plaques and showed that CD146 participates to the formation of foam cells and their retention within the plaque?. However, unlike this study, we did not observe any reduction of LDL uptake by CD146 deficient macrophages in vitro (Supplemental Figure 7), which is also consistent with the absence of difference we observed in early foam-cells-enriched plaques after 12 weeks of Western diet (Supplemental Figure $1 \mathrm{~A}$ ). Thus, we sought to further decipher the role of CD146 during atherogenesis using CD146 -/-/ApoE -/- mice.

CD146 -/-/ApoE -/- mice and ApoE -/- mice were fed a Western diet for 24 weeks, a diet known to induce atherosclerotic plaques along the aortic root and thoraco-abdominal aorta ${ }^{33}$. Our results demonstrated that the genetic deletion of CD146 in ApoE -/- mice significantly increased atherosclerotic plaque size. We also showed augmented arterial wall thickness using high frequency ultrasound, confirming the usefulness of this non-invasive imaging method to monitor atherosclerosis progression. In addition, we found that CD146 -/-/ApoE -/plaques were more inflammatory and prone to rupture, as evidenced by higher neutrophil and macrophage infiltration, suggesting that CD146 could be atheroprotective. These results may appear contradictory with those from a recent study showing that CD146 could be proatherogenic because it promotes foam cell accumulation within atherosclerotic lesions ${ }^{7}$. One 
can suppose that systemic genetic deletion and antibody treatment (used in the Luo's study for atherosclerosis prevention in mice) may generally produce similar effects but here, we have demonstrated opposed results, maybe due to the nature of the administrated antibody. Actually, Luo et al. used the anti-human CD146 AA98 antibody they previously generated and characterized as an antibody that targets human CD146 expressed on stimulated HUVECs but not primary HUVECs, and that preferentially stains blood vessels from human tumor tissues $(97,4 \%)$ and only $18,8 \%$ of blood vessels from normal human tissues ${ }^{34}$. In addition, in this study, the authors investigated the role of macrophagic CD146 during atherosclerosis only by transferring CD146-null myeloid cell lineage in ApoE -/atherosclerotic mice, which could lead to results different from the systemic genetic deletion used in our study ${ }^{35}$. Here, we analyzed more global mechanisms accounting for leukocyte recruitment during atherosclerosis in CD146 -/-/ApoE -/- mice and found out that CD146 controls RANTES secretion by macrophages and the subsequent chemotaxis of neutrophils and macrophages. Altogether, our results showed that there was a shift in plaque composition towards unstable lesions since CD146-deficient plaques contained approximately $47 \%$ macrophages and $32 \%$ SMC versus $31 \%$ macrophages and $43 \%$ SMC in the presence of CD146. We could not exclude that other cells such as T cells influence plaque size and composition, notably we observed a trend to a decrease in CD3 T cells in CD146 deficient mice (data not shown) but as it did not reach a statistical difference, we focused our study on neutrophils.

We evidenced that RANTES was upregulated in CD146 -/-/ApoE -/- arteries, and was involved in the accumulation of neutrophils and macrophages within the growing atheroma. Chemokines are small soluble molecules that are best known for their potent abilities to direct leukocytes to sites of inflammation. They may also control homeostasis and other activities of emigrated cells ${ }^{36}$. RANTES, also known as CCL5, plays an essential role in inflammation and atherogenesis ${ }^{31,37}$. In addition to its expression by atherosclerotic plaque cells, RANTES can also be deposited on early atherosclerotic endothelium, where it can trigger the arrest of circulating neutrophils and monocytes ${ }^{38}$. Interestingly, we found that 
plasmatic levels of RANTES were also significantly increased in CD146 -/-/ApoE -/- mice during atherosclerosis. As a consequence of RANTES elevation, we also demonstrated that CD146 deficiency led to neutrophilia as evidenced by the significant increase of circulating Ly6G-positive neutrophils during atherosclerosis. Furthermore, the administration of a RANTES receptor antagonist, Maraviroc, abolished the increased neutrophilia and the accelerated atherosclerosis in CD146-/- ApoE-/- mice when compared to ApoE-/- mice. Elevated numbers of circulating neutrophils have been shown to be predictive of cardiovascular events, independently of serum cholesterol levels ${ }^{39}$. In line with this, Drechsler et al. demonstrated a direct correlation between the number of circulating neutrophils and lesional neutrophils and atherosclerotic plaque size ${ }^{40}$. Neutrophils are involved in the initiation and progression of atherosclerosis since they accumulate early in large arteries ${ }^{40-43}$, then degranulate and trigger the rapid recruitment of inflammatory monocytes ${ }^{43-45}$. The preferential recruitment of neutrophils and monocytes into atherosclerotic arteries relies on chemokine-dependent signaling, notably through the RANTES/CCR5 interaction ${ }^{46-48}$, and neutralizing this axis reduced atherosclerosis ${ }^{49}$. We also demonstrated that plasmatic RANTES levels were significantly correlated with neutrophil accumulation in mice atheroma. Furthermore, previous studies have shown positive associations between RANTES and carotid wall thickness as well as lipid-core volume in humans ${ }^{50}$. RANTES is now established to be important for maintaining leukocyte homeostasis. It was previously demonstrated that RANTES influences hematopoietic stem cell subtypes by directing them toward myeloid differentiation at the expense of lymphoid differenciation. Thus, in addition to blood, we have also to consider the leukocytes subpopulations in spleen and in aorta in order to propose a mechanism of leukocytes mobilization in atherosclerotic mice overexpressing CCL5 in our study. In this way, we prepared single cell suspensions of the spleen and aorta and analyzed macrophages, neutrophiles, CD4 and CD8 T cells. We did not observe any difference of macrophages, neutrophiles or T cells between ApoE -/- and ApoE -/- CD146 -/- mice both in aorta and spleen (data not shown). We only evidenced that CD146 deficient bone marrow-derived 
myeloid cells produced significantly higher levels of RANTES compared to WT myeloid cells harboring CD146. Altogether, our results showed that CD146 deficiency upregulated RANTES both at the transcriptomic and protein levels, which could explain the neutrophilia observed when CD146 was absent. In addition, upregulated RANTES led to leukocytes transmigration, neutrophils and macrophages accumulation within growing atheroma. Another major finding of this study is that CD146-deficient bone marrow-derived macrophages produced significantly higher levels of RANTES as compared to cells harboring CD146, not only during atherogenesis but also at the basal state. These data indicate that there is a defect of RANTES regulation in macrophages when CD146 is absent. Our results are in line with the literature since a previous study showed that an increase of CD146 in T-lymphocytes was associated with a decrease of RANTES production ${ }^{51}$. It was also previously shown that RANTES production was increased with CD146 knockdown in cancer-associated fibroblasts whereas it was decreased with CD146 overexpression in the same cells ${ }^{52}$. In non-atherosclerotic conditions, there is no consequence on plasmatic RANTES as evidenced by similar low levels of circulating RANTES between WT and CD146 KO mice. We could also exclude that CD146-associated neutrophilia is due to the different genetic background for ApoE since we did not detect any differences of circulating neutrophils or RANTES between young ApoE -/- and ApoE -/- CD146 -/- mice fed a standard chow diet. However, during atherosclerosis, the chronic inflammatory state induced by both atherosclerosis and Western diet allows to reveal this defect of RANTES regulation and neutrophilia.

In addition, it was previously shown that macrophages within atherosclerotic plaques overexpress CD146, 25 and we evidenced that CD146-null macrophages are a main source of RANTES within atheroma. Thus, CD146-deficient atheroma produced more RANTES and because atheroma could release parts of its content, plasmatic RANTES might be increased in CD146-deficient animals as a consequence. This could also explain why we did not detect any difference in RANTES plasmatic levels after 12 weeks of Western diet, as foam cellenriched plaques may be needed to reveal the defect of RANTES secretion. Indeed, 
RANTES positive area in plaques significantly augmented only from $0.5 \%$ in apoE-/- mice to $1 \%$ in CD146-/-apoE-/- mice and we observed almost a two-fold increase in plasmatic RANTES level. However, our study has some limitations. Since CD146 and RANTES are expressed by many cell types, the increased plasmatic RANTES observed in CD146 deficient mice could be the result of both increased atherosclerotic macrophages and increased inflammatory circulating cells which are source of RANTES. In addition, other cellspecific CD146-deficient atherosclerotic animals could be studied or further bone marrow transplantation studies should be performed to confirm the role of CD146-deficient BMDMderived cells in atherogenesis. We investigated the mechanisms underlying RANTES upregulation in BMDM derived from ApoE-/- and CD146-/- ApoE-/- mice. NF-kB is a known inducer of RANTES transcription whilst activated p38 is a repressor. We did not detect any difference in NF-KB signaling, however we observed a significant decrease of p38-MAPK activation and increase of RANTES secretion in CD146-/- ApoE-/- BMDM supernatant.

Our results indicated that CD146 deficiency in macrophages led to the inhibition of p38MAPK phosphorylation and subsequent RANTES over-secretion. It was previously shown that p38-MAPK signaling inhibits mRNA RANTES expression and protein production ${ }^{53}$ without affecting NF-KB gene transcription or transcription factor activation ${ }^{54,55}$. Our results are consistent with previous studies demonstrating that CD146 was required for p38-MAPK activation $^{56}$ and that p38-MAPK activation was inhibited in CD146-null endothelial cells ${ }^{57}$. In addition, our data demonstrate that CD146 could be necessary to control RANTES secretion through a constitutive p38-MAPK activation possibly downstream of VEGFR-2 activation. Since CD146 was previously described to be involved in VEGFR-2 phosphorylation ${ }^{8,56}$, we propose that RANTES production is regulated by CD146/VEGFR-2 and p38-MAPK signaling pathways (schematic model in Supplemental Figure 6). Addition of a p38-MAPK or VEGFR-2 inhibitor on macrophages expressing CD146 in culture significantly increased their RANTES secretion to similar levels as those of CD146-null macrophages. Altogether, our results showed that CD146 deficiency upregulated RANTES through the p38-MAPK signaling pathway. Increased circulating RANTES led to excessive neutrophilia and further participated 
to amplify neutrophil and macrophage accumulation within growing atheroma, thus promoting inflammatory and unstable plaques. Targeting inflammatory chemokines has been proposed as an alternative therapeutic strategy in order to control leukocyte accumulation during human atherosclerosis ${ }^{58-60}$. However, it is still a considerable challenge since chemokine antagonists could have unwanted side effects. In addition, because p38-MAPK is ubiquitous, it seems harmful to directly target it in order to control RANTES production. Therefore, our results identify macrophagic CD146 as a potential target opening new perspectives for the prevention and treatment of atherosclerosis.

Sources of funding: This work was supported by institutional resources provided by AixMarseille University, INSERM and by a grant from the Fondation de France. MG. Blin is the recipient of a doctoral fellowship from the PACA Region and is supported by Inserm and Region Fundings.

Acknowledgements: None

Conflict of Interest: None 
1. Bardin N, Anfosso F, Masse JM, Cramer E, Sabatier F, Le Bivic A, Sampol J, DignatGeorge F. Identification of cd146 as a component of the endothelial junction involved in the control of cell-cell cohesion. Blood. 2001;98:3677-3684

2. George F, Brisson C, Poncelet P, Laurent JC, Massot O, Arnoux D, Ambrosi P, KleinSoyer C, Cazenave JP, Sampol J. Rapid isolation of human endothelial cells from whole blood using s-endo1 monoclonal antibody coupled to immuno-magnetic beads: Demonstration of endothelial injury after angioplasty. Thromb Haemost. 1992;67:147153

3. Pickl WF, Majdic O, Fischer GF, Petzelbauer P, Fae I, Waclavicek M, Stockl J, Scheinecker C, Vidicki T, Aschauer H, Johnson JP, Knapp W. Muc18/mcam (cd146), an activation antigen of human t lymphocytes. J Immunol. 1997;158:2107-2115

4. Despoix N, Walzer T, Jouve N, Blot-Chabaud M, Bardin N, Paul P, Lyonnet L, Vivier E, Dignat-George F, Vely F. Mouse cd146/mcam is a marker of natural killer cell maturation. Eur J Immunol. 2008;38:2855-2864

5. Ouhtit A, Gaur RL, Abd Elmageed ZY, Fernando A, Thouta R, Trappey AK, Abdraboh ME, El-Sayyad HI, Rao P, Raj MG. Towards understanding the mode of action of the multifaceted cell adhesion receptor cd146. Biochim Biophys Acta. 2009;1795:130-136

6. Qian YN, Luo YT, Duan HX, Feng LQ, Bi Q, Wang YJ, Yan XY. Adhesion molecule cd146 and its soluble form correlate well with carotid atherosclerosis and plaque instability. CNS Neurosci Ther. 2014;20:438-445

7. Luo Y, Duan H, Qian Y, Feng L, Wu Z, Wang F, Feng J, Yang D, Qin Z, Yan X. Macrophagic cd146 promotes foam cell formation and retention during atherosclerosis. Cell Res. 2017;27:352-372

8. Jouve N, Bachelier R, Despoix N, Blin MG, Matinzadeh MK, Poitevin S, AurrandLions M, Fallague K, Bardin N, Blot-Chabaud M, Vely F, Dignat-George F, Leroyer AS. Cd146 mediates vegf-induced melanoma cell extravasation through fak activation. Int J Cancer. 2014

9. Anfosso F, Bardin N, Frances V, Vivier E, Camoin-Jau L, Sampol J, Dignat-George F. Activation of human endothelial cells via s-endo-1 antigen (cd146) stimulates the tyrosine phosphorylation of focal adhesion kinase p125(fak). J Biol Chem. 1998;273:26852-26856

10. Anfosso F, Bardin N, Vivier E, Sabatier F, Sampol J, Dignat-George F. Outside-in signaling pathway linked to cd146 engagement in human endothelial cells. $J$ Biol Chem. 2001;276:1564-1569

11. Bu P, Gao L, Zhuang J, Feng J, Yang D, Yan X. Anti-cd146 monoclonal antibody aa98 inhibits angiogenesis via suppression of nuclear factor-kappab activation. $\mathrm{Mol}$ Cancer Ther. 2006;5:2872-2878

12. Jiang T, Zhuang J, Duan H, Luo Y, Zeng Q, Fan K, Yan H, Lu D, Ye Z, Hao J, Feng $\mathrm{J}$, Yang D, Yan X. Cd146 is a co-receptor for vegfr-2 in tumor angiogenesis. Blood. 2012

13. Bardin N, Blot-Chabaud M, Despoix N, Kebir A, Harhouri K, Arsanto JP, Espinosa L, Perrin P, Robert S, Vely F, Sabatier F, Le Bivic A, Kaplanski G, Sampol J, DignatGeorge F. Cd146 and its soluble form regulate monocyte transendothelial migration. Arteriosclerosis, thrombosis, and vascular biology. 2009;29:746-753

14. Flanagan K, Fitzgerald K, Baker J, Regnstrom K, Gardai S, Bard F, Mocci S, Seto P, You M, Larochelle C, Prat A, Chow S, Li L, Vandevert C, Zago W, Lorenzana C, Nishioka C, Hoffman J, Botelho R, Willits C, Tanaka K, Johnston J, Yednock T. Laminin-411 is a vascular ligand for mcam and facilitates th17 cell entry into the cns. PLoS One. 2012;7:e40443

15. Guezguez B, Vigneron P, Lamerant N, Kieda C, Jaffredo T, Dunon D. Dual role of melanoma cell adhesion molecule (mcam)/cd146 in lymphocyte endothelium interaction: Mcam/cd146 promotes rolling via microvilli induction in lymphocyte and is an endothelial adhesion receptor. J Immunol. 2007;179:6673-6685

16. Larochelle C, Cayrol R, Kebir H, Alvarez JI, Lecuyer MA, Ifergan I, Viel E, Bourbonniere L, Beauseigle D, Terouz S, Hachehouche L, Gendron S, Poirier J, 
Jobin C, Duquette P, Flanagan K, Yednock T, Arbour N, Prat A. Melanoma cell adhesion molecule identifies encephalitogenic $t$ lymphocytes and promotes their recruitment to the central nervous system. Brain. 2012;135:2906-2924

17. Wu Q, Case SR, Minor MN, Jiang D, Martin RJ, Bowler RP, Wang J, Hartney J, Karimpour-Fard A, Chu HW. A novel function of muc18: Amplification of lung inflammation during bacterial infection. Am J Pathol. 2013;182:819-827

18. Bardin N, Moal V, Anfosso F, Daniel L, Brunet P, Sampol J, Dignat George F. Soluble cd146, a novel endothelial marker, is increased in physiopathological settings linked to endothelial junctional alteration. Thromb Haemost. 2003;90:915-920

19. Bardin N, Reumaux D, Geboes K, Colombel JF, Blot-Chabaud M, Sampol J, Duthilleul P, Dignat-George F. Increased expression of cd146, a new marker of the endothelial junction in active inflammatory bowel disease. Inflammatory bowel diseases. 2006;12:16-21

20. Dagur PK, Biancotto A, Wei L, Sen HN, Yao M, Strober W, Nussenblatt RB, McCoy JP, Jr. Mcam-expressing cd4(+) t cells in peripheral blood secrete il-17a and are significantly elevated in inflammatory autoimmune diseases. $J$ Autoimmun. 2011;37:319-327

21. Figarella-Branger D, Schleinitz N, Boutiere-Albanese B, Camoin L, Bardin N, Guis S, Pouget J, Cognet C, Pellissier JF, Dignat-George F. Platelet-endothelial cell adhesion molecule-1 and cd146: Soluble levels and in situ expression of cellular adhesion molecules implicated in the cohesion of endothelial cells in idiopathic inflammatory myopathies. J Rheumatol. 2006;33:1623-1630

22. Middleton J, Americh L, Gayon R, Julien D, Mansat M, Mansat $P$, Anract $P$, Cantagrel A, Cattan P, Reimund JM, Aguilar L, Amalric F, Girard JP. A comparative study of endothelial cell markers expressed in chronically inflamed human tissues: Meca-79, duffy antigen receptor for chemokines, von willebrand factor, cd31, cd34, cd105 and cd146. J Pathol. 2005;206:260-268

23. Reumaux D, Bardin N, Colombel JF, Dignat-George F, Duthilleul P, Vermeire S. Restoration of soluble cd146 in patients with crohn's disease treated with the tnfalpha antagonist infliximab. Inflammatory bowel diseases. 2007;13:1315-1317

24. Schulz C, Petrig V, Wolf K, Kratzel K, Kohler M, Becker B, Pfeifer M. Upregulation of mcam in primary bronchial epithelial cells from patients with copd. Eur Respir J. 2003;22:450-456

25. Ciftci Dogansen S, Helvaci A, Adas M, Deniz Onal S. The relationship between early atherosclerosis and endothelial dysfunction in type 1 diabetic patients as evidenced by measurement of carotid intima-media thickness and soluble cd146 levels: A cross sectional study. Cardiovasc Diabetol. 2013;12:153

26. Hansson GK, Hermansson A. The immune system in atherosclerosis. Nature immunology. 2011;12:204-212

27. Hansson GK, Libby P. The immune response in atherosclerosis: A double-edged sword. Nature reviews. Immunology. 2006;6:508-519

28. Swirski FK, Libby P, Aikawa E, Alcaide P, Luscinskas FW, Weissleder R, Pittet MJ. Ly-6chi monocytes dominate hypercholesterolemia-associated monocytosis and give rise to macrophages in atheromata. J Clin Invest. 2007;117:195-205

29. Call DR, Nemzek JA, Ebong SJ, Bolgos GL, Newcomb DE, Remick DG. Ratio of local to systemic chemokine concentrations regulates neutrophil recruitment. Am J Pathol. 2001;158:715-721

30. Murphy AJ, Sarrazy V, Wang N, Bijl N, Abramowicz S, Westerterp M, Welch CB, Schuetz JD, Yvan-Charvet L. Deficiency of atp-binding cassette transporter b6 in megakaryocyte progenitors accelerates atherosclerosis in mice. Arteriosclerosis, thrombosis, and vascular biology. 2014;34:751-758

31. Veillard NR, Kwak B, Pelli G, Mulhaupt F, James RW, Proudfoot AE, Mach F. Antagonism of rantes receptors reduces atherosclerotic plaque formation in mice. Circ Res. 2004;94:253-261 
32. Homma T, Matsukura S, Hirose T, Ohnishi T, Kimura T, Kurokawa M, leki K, Odaka M, Suzuki S, Watanabe S, Sato M, Kawaguchi M, Schleimer RP, Adachi M. Cooperative activation of ccl5 expression by tlr3 and tumor necrosis factor-alpha or interferon-gamma through nuclear factor-kappab or stat-1 in airway epithelial cells. Int Arch Allergy Immunol. 2010;152 Suppl 1:9-17

33. Breslow JL. Mouse models of atherosclerosis. Science. 1996;272:685-688

34. Yan X, Lin Y, Yang D, Shen Y, Yuan M, Zhang Z, Li P, Xia H, Li L, Luo D, Liu Q, Mann K, Bader BL. A novel anti-cd146 monoclonal antibody, aa98, inhibits angiogenesis and tumor growth. Blood. 2003;102:184-191

35. Schiller NK, Kubo N, Boisvert WA, Curtiss LK. Effect of gamma-irradiation and bone marrow transplantation on atherosclerosis in Idl receptor-deficient mice. Arteriosclerosis, thrombosis, and vascular biology. 2001;21:1674-1680

36. Charo IF, Ransohoff RM. The many roles of chemokines and chemokine receptors in inflammation. The New England journal of medicine. 2006;354:610-621

37. Baltus T, Weber KS, Johnson Z, Proudfoot AE, Weber C. Oligomerization of rantes is required for ccr1-mediated arrest but not ccr5-mediated transmigration of leukocytes on inflamed endothelium. Blood. 2003;102:1985-1988

38. von Hundelshausen P, Weber KS, Huo Y, Proudfoot AE, Nelson PJ, Ley K, Weber C. Rantes deposition by platelets triggers monocyte arrest on inflamed and atherosclerotic endothelium. Circulation. 2001;103:1772-1777

39. Guasti L, Dentali F, Castiglioni L, Maroni L, Marino F, Squizzato A, Ageno W, Gianni M, Gaudio G, Grandi AM, Cosentino M, Venco A. Neutrophils and clinical outcomes in patients with acute coronary syndromes and/or cardiac revascularisation. A systematic review on more than 34,000 subjects. Thromb Haemost. 2011;106:591599

40. Drechsler M, Megens RT, van Zandvoort M, Weber C, Soehnlein O. Hyperlipidemiatriggered neutrophilia promotes early atherosclerosis. Circulation. 2010;122:18371845

41. Soehnlein O. Multiple roles for neutrophils in atherosclerosis. Circ Res. 2012;110:875-888

42. van Leeuwen M, Gijbels MJ, Duijvestijn A, Smook M, van de Gaar MJ, Heeringa P, de Winther MP, Tervaert JW. Accumulation of myeloperoxidase-positive neutrophils in atherosclerotic lesions in Idlr-/- mice. Arteriosclerosis, thrombosis, and vascular biology. 2008;28:84-89

43. Zernecke A, Bot I, Djalali-Talab Y, Shagdarsuren E, Bidzhekov K, Meiler S, Krohn R, Schober A, Sperandio M, Soehnlein O, Bornemann J, Tacke F, Biessen EA, Weber C. Protective role of Cxc receptor 4/cxc ligand 12 unveils the importance of neutrophils in atherosclerosis. Circ Res. 2008;102:209-217

44. Soehnlein O, Lindbom L. Phagocyte partnership during the onset and resolution of inflammation. Nature reviews. Immunology. 2010;10:427-439

45. Weber C, Noels H. Atherosclerosis: Current pathogenesis and therapeutic options. Nat Med. 2011;17:1410-1422

46. Braunersreuther V, Zernecke A, Arnaud C, Liehn EA, Steffens S, Shagdarsuren E, Bidzhekov K, Burger F, Pelli G, Luckow B, Mach F, Weber C. Ccr5 but not ccr1 deficiency reduces development of diet-induced atherosclerosis in mice. Arteriosclerosis, thrombosis, and vascular biology. 2007;27:373-379

47. Doring Y, Drechsler M, Soehnlein O, Weber C. Neutrophils in atherosclerosis: From mice to man. Arteriosclerosis, thrombosis, and vascular biology. 2015;35:288-295

48. Tacke F, Alvarez D, Kaplan TJ, Jakubzick C, Spanbroek R, Llodra J, Garin A, Liu J, Mack M, van Rooijen N, Lira SA, Habenicht AJ, Randolph GJ. Monocyte subsets differentially employ ccr2, ccr5, and $\mathrm{cx3}$ cr1 to accumulate within atherosclerotic plaques. J Clin Invest. 2007;117:185-194

49. Combadiere C, Potteaux S, Rodero M, Simon T, Pezard A, Esposito B, Merval R, Proudfoot A, Tedgui A, Mallat Z. Combined inhibition of ccl2, cx3cr1, and ccr5 
abrogates ly6c(hi) and ly6c(lo) monocytosis and almost abolishes atherosclerosis in hypercholesterolemic mice. Circulation. 2008;117:1649-1657

50. Virani SS, Nambi V, Hoogeveen R, Wasserman BA, Coresh J, Gonzalez F, 2nd, Chambless LE, Mosley TH, Boerwinkle E, Ballantyne CM. Relationship between circulating levels of rantes (regulated on activation, normal t-cell expressed, and secreted) and carotid plaque characteristics: The atherosclerosis risk in communities (aric) carotid mri study. Eur Heart J. 2011;32:459-468

51. Dagur PK, Tatlici G, Gourley M, Samsel L, Raghavachari N, Liu P, Liu D, McCoy JP, Jr. Cd146+ $t$ lymphocytes are increased in both the peripheral circulation and in the synovial effusions of patients with various musculoskeletal diseases and display proinflammatory gene profiles. Cytometry B Clin Cytom. 2010;78:88-95

52. Zheng B, Ohuchida K, Chijiiwa Y, Zhao M, Mizuuchi Y, Cui L, Horioka K, Ohtsuka T, Mizumoto K, Oda Y, Hashizume M, Nakamura M, Tanaka M. Cd146 attenuation in cancer-associated fibroblasts promotes pancreatic cancer progression. Mol Carcinog. 2016;55:1560-1572

53. Liu H, Ning H, Men H, Hou R, Fu M, Zhang H, Liu J. Regulation of ccl5 expression in smooth muscle cells following arterial injury. PLoS One. 2012;7:e30873

54. Adada MM, Orr-Gandy KA, Snider AJ, Canals D, Hannun YA, Obeid LM, Clarke CJ. Sphingosine kinase 1 regulates tumor necrosis factor-mediated rantes induction through p38 mitogen-activated protein kinase but independently of nuclear factor kappab activation. J Biol Chem. 2013;288:27667-27679

55. Pazdrak K, Olszewska-Pazdrak B, Liu T, Takizawa R, Brasier AR, Garofalo RP, Casola A. Mapk activation is involved in posttranscriptional regulation of rsv-induced rantes gene expression. Am J Physiol Lung Cell Mol Physiol. 2002;283:L364-372

56. Jiang T, Zhuang J, Duan H, Luo Y, Zeng Q, Fan K, Yan H, Lu D, Ye Z, Hao J, Feng J, Yang D, Yan X. Cd146 is a coreceptor for vegfr-2 in tumor angiogenesis. Blood. 2012;120:2330-2339

57. Zeng Q, Wu Z, Duan H, Jiang X, Tu T, Lu D, Luo Y, Wang P, Song L, Feng J, Yang $\mathrm{D}$, Yan $\mathrm{X}$. Impaired tumor angiogenesis and vegf-induced pathway in endothelial cd146 knockout mice. Protein Cell. 2014;5:445-456

58. Dorgham K, Ghadiri A, Hermand P, Rodero M, Poupel L, Iga M, Hartley O, Gorochov G, Combadiere C, Deterre P. An engineered cx3cr1 antagonist endowed with antiinflammatory activity. Journal of leukocyte biology. 2009;86:903-911

59. McDermott DH, Fong AM, Yang Q, Sechler JM, Cupples LA, Merrell MN, Wilson PW, D'Agostino RB, O'Donnell CJ, Patel DD, Murphy PM. Chemokine receptor mutant cx3cr1-m280 has impaired adhesive function and correlates with protection from cardiovascular disease in humans. J Clin Invest. 2003;111:1241-1250

60. Norata GD, Garlaschelli K, Ongari M, Raselli S, Grigore L, Catapano AL. Effects of fractalkine receptor variants on common carotid artery intima-media thickness. Stroke. 2006;37:1558-1561 


\section{Figure Legends}

Figure 1. Atherosclerotic plaques from CD146-deficient mice are increased and more inflammatory

A. Representative Oil red O-stained aortae from male mice after 24 weeks of Western diet (left) and quantification of the en face lesion area (right) $(n=10$ each group, $p=0.004)$ (Leica, DMI8, 5X). B. Representative photographs of Oil Red O staining of the aortic sinus of ApoE /- and CD146 -/-/ApoE -/- male mice (left) and quantification (right) ( $\mathrm{n}=6$ each group, $\mathrm{p}=0.001$ ) (Leica, DMI8, 10X). C. Representative photographs of MOMA-2 staining (brownred) in the aortic sinus of ApoE -/- and CD146 -/-/ApoE -/- male mice after 24 weeks of Western diet showing macrophage accumulation within the lesions (left) and quantitative analysis of MOMA-2 staining (\% macrophage-positive area/plaque area, right) ( $\mathrm{n}=6$ each group, $p=0.029$ ). D. Representative photographs of Ly6G-FITC staining in the aortic sinus of ApoE -/- and CD146 -/-/ApoE -/- male mice after 24 weeks of Western diet showing neutrophil accumulation within the lesions (left) and quantitative analysis of Ly6G staining (\% neutrophil-positive area/plaque area, right) ( $n=6$ each group, $p=0.032$ ). E. Representative photographs of neutrophil elastase (NE) (brown-red) staining in the aortic sinus of ApoE -/and CD146 -/-/ApoE -/- male mice after 24 weeks of Western diet (left) and quantitative analysis of NE staining (\% NE-positive area/plaque area, right) ( $n=6$ each group, $p=0.041)$. Plaques labeled with only corresponding secondary antibodies were used as controls. The data are shown as the mean \pm SEM, ${ }^{*} p<0.05,{ }^{* *} p<0.01$.

\section{Figure 2. CD146 deficiency triggers neutrophilia and upregulation of RANTES}

A. Representative examples of circulating neutrophil labeling (left) and quantification of their numbers (right) ( $n=6$ each group, $p=0.002$ ). B. Representative examples of circulating monocyte labeling and quantification of their numbers (left). Relative levels of Ly6C low and Ly6C high monocytes ( $\%$ of circulating levels) (right) ( $n=6$ each group). C. Circulating RANTES was quantified in plasma collected from ApoE-/- and CD146 -/-/ ApoE-/- male mice 
after 24 weeks of Western diet $(n=6$ each group, $p=0.02)$. D. Correlation of plasmatic RANTES with the percentage of neutrophils in plaques ( $n=6$ each group, $p=0.02)$. E. Representative photographs of DAPI (blue), RANTES-FITC (green) staining in the aortic sinus of ApoE -/- and CD146 -/-/ApoE -/- male mice (left) and quantitative analysis of staining (\% RANTES-positive area/plaque area, right) ( $n=5$ each group, $p=0.05)$. F. Representative photographs of DAPI (blue), MOMA-2 (red) and RANTES (green) staining in the aortic sinus of ApoE -/- and CD146 -/-/ApoE -/- male mice ( $\mathrm{n}=5$ each group) (left) (Leica, DMi18, 20X) and degree of RANTES/MOMA-2 colocalization (right). The data are shown as the mean $\pm S E M,{ }^{*} p<0.05,{ }^{* *} p<0.01$. All mice were fed a Western diet.

\section{Figure 3. CD146-mediated RANTES regulation is dependent on p38-MAPK activation}

A. RANTES production by ApoE-/- and CD146 -/-/ ApoE-/- bone-marrow derived macrophages (BMDM) after 7 days of culture ( $n=4$ each group, $p=0.026$ ) was detected by ELISA. B. Cultured BMDM from ApoE-/- and CD146 -/-/ ApoE-/- mice were lyzed. The p38MAPK and VEGFR-2 phosphorylations were detected by Western blotting (left). Quantification of the p38 and VEGFR-2 activation were determined by measuring the band density ratios of phosphorylated proteins/total proteins (right) ( $n=4$ each group, $p=0.029$ ). C. RANTES production by BMDM cultured with VEGFR-2 inhibitor Sunitinib or p38-MAPK inhibitor SB203580 ( $n=4$ each group). D. Representative photographs of p38 staining (brown) of aortic sinus from male mice after 24 weeks of Western diet (left) and quantification (right) $(n=6$ each group, $p=0.004)$ (Leica, DMl8, $5 X$ ). The data are shown as the mean $\pm S E M$, ${ }^{*} p<0.05$.

Figure 4. Administration of RANTES receptor antagonist abolishes the increased neutrophil recruitment in CD146 null mice during atherosclerosis and decreases plaque size

A. Representative Oil red O-stained aortae from male mice after 24 weeks of Western diet treated with Maraviroc (50 mg/kg, daily from 12 weeks to 24 weeks of Western diet) or 
vehicle (corn oil) (left) and quantification of the en face lesion area (right) ( $n=4$ each group, $\mathrm{p}=0.029$ ) (Leica, DMl8, 5X). B. Representative photographs of Oil Red O staining of the aortic sinus of ApoE -/- and CD146 -/-/ApoE -/- male mice (left) and quantification (right) ( $\mathrm{n}=4$ each group, $p=0.029$ ) (Leica, DMI8, 10X). C. Representative photographs of Ly6G staining in the aortic sinus of ApoE -/- and CD146 -/-/ApoE -/- male mice showing neutrophil accumulation within the lesions (left) and quantitative analysis of Ly6G staining (\% neutrophil positive area/plaque area, right) ( $n=4$ each group, $p=0.029$ ). $D$. Representative examples of circulating neutrophil labeling (left) and quantification of their numbers (right) ( $\mathrm{n}=4$ each group, $p=0.029)$. The data are shown as the mean $\pm S E M,{ }^{*} p<0.05$. 
A

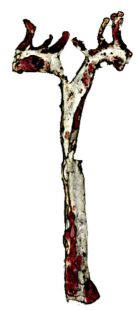

ApoE - /-

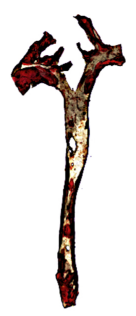

CD146 -I-IApoE -/-

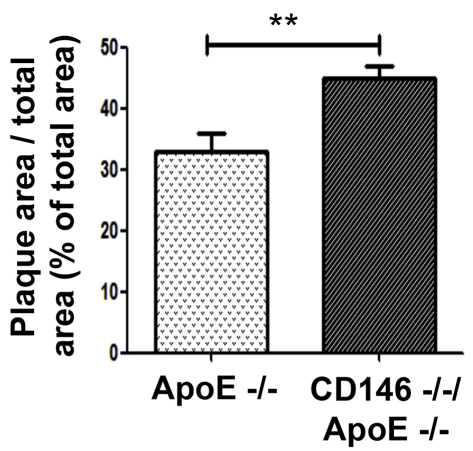

B
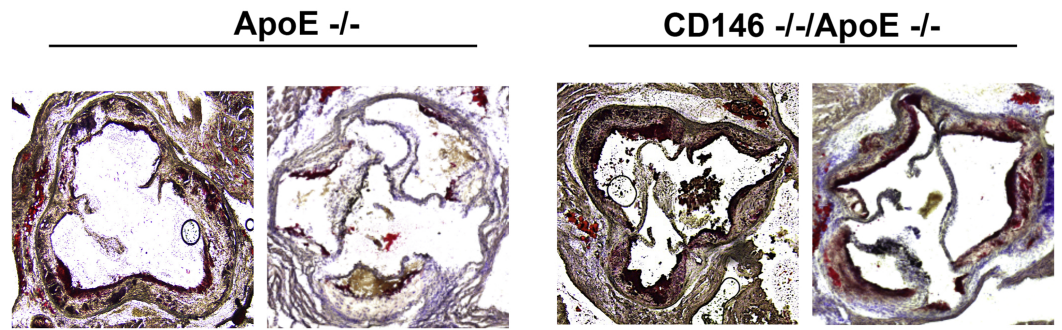

C ApoE -I-

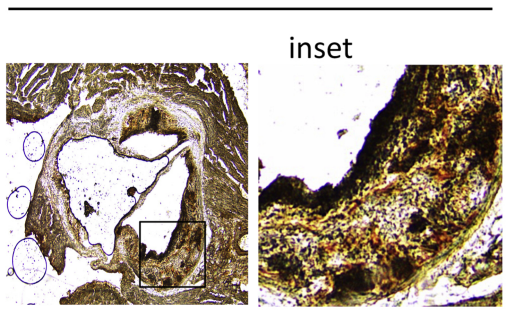

D

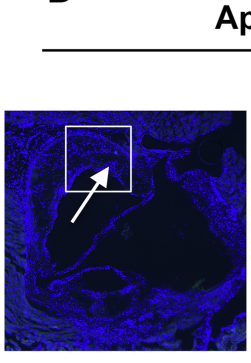

ApoE -/-

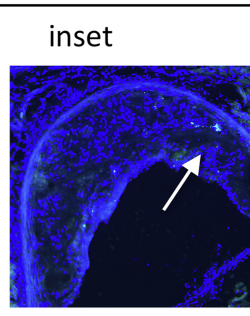

E

ApoE -/-

\section{inset}

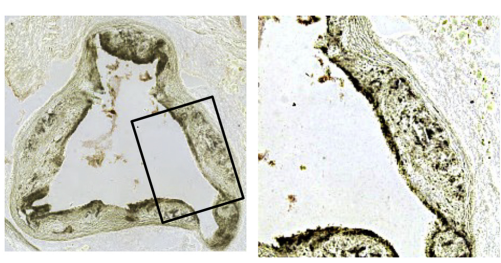

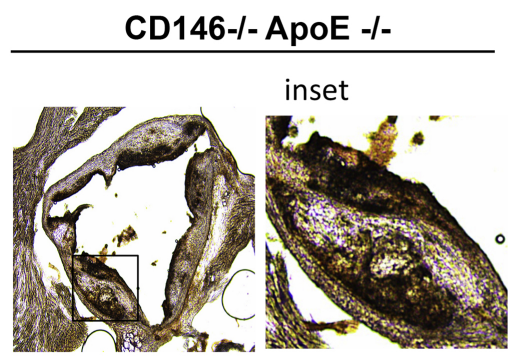

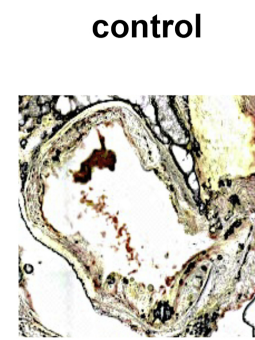

CD146-/- ApoE -/-

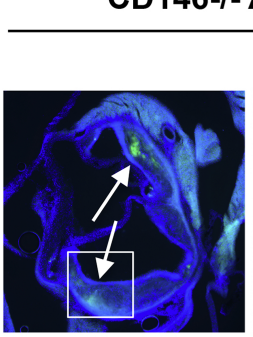

inset

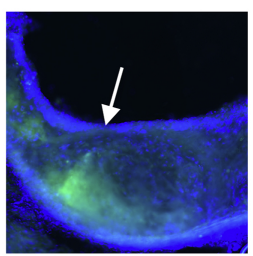

CD146-/-ApoE -/-

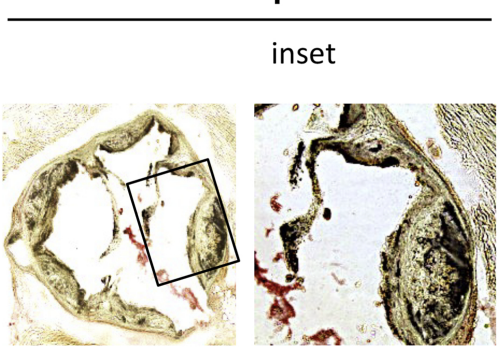

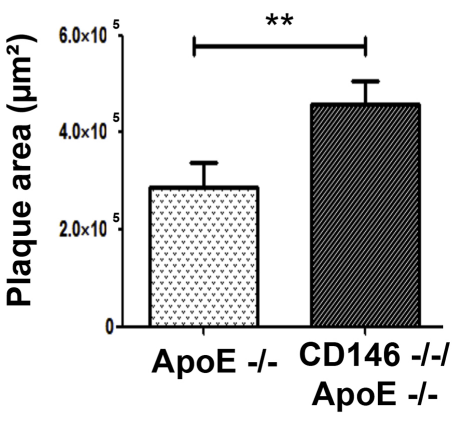
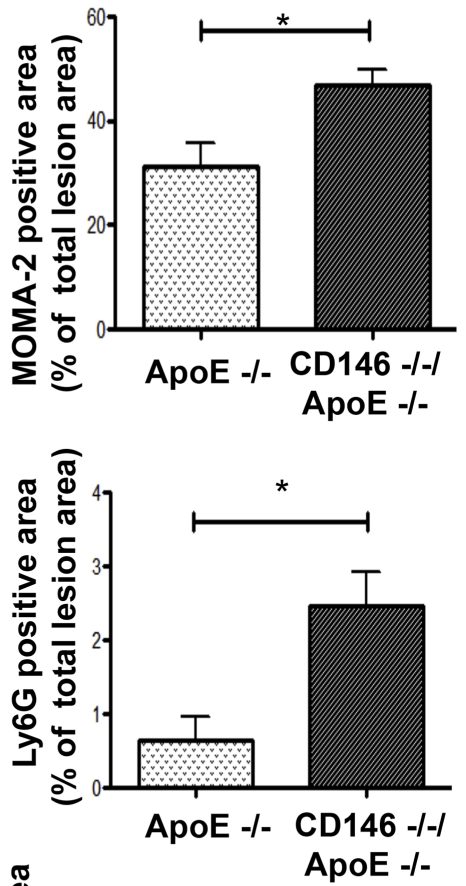

control

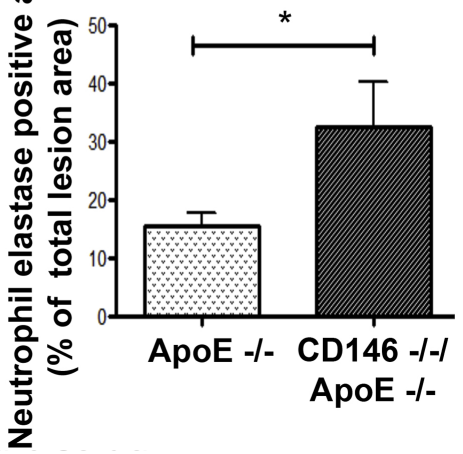


A

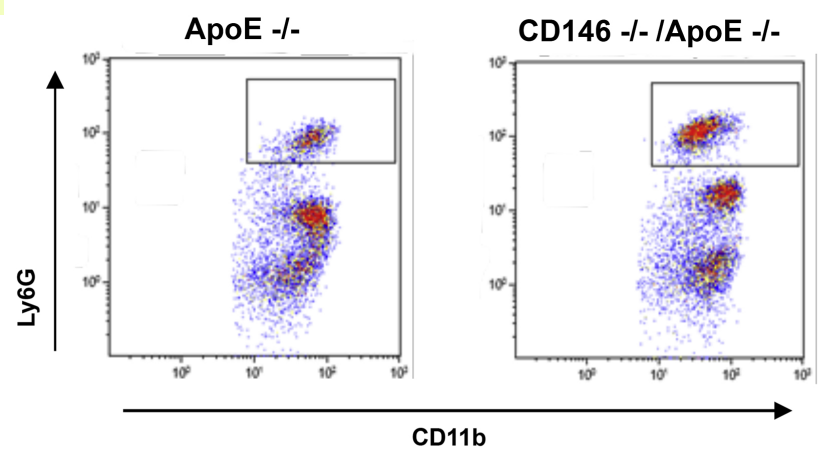

B

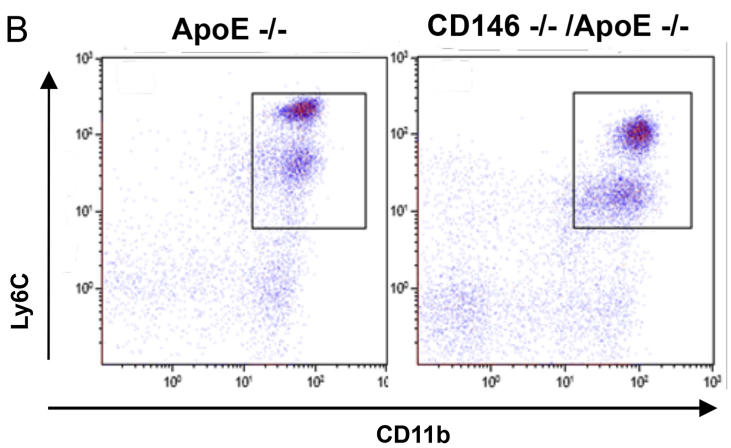

C

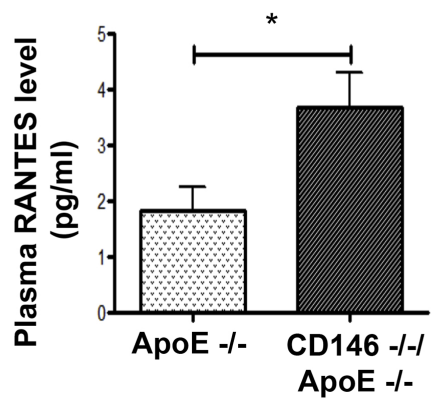

E

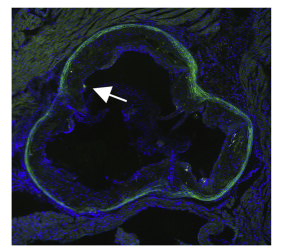

ApoE -/-

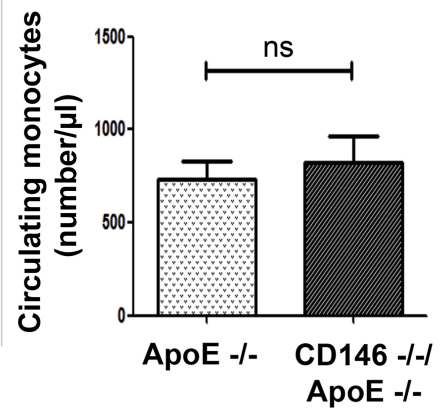

D
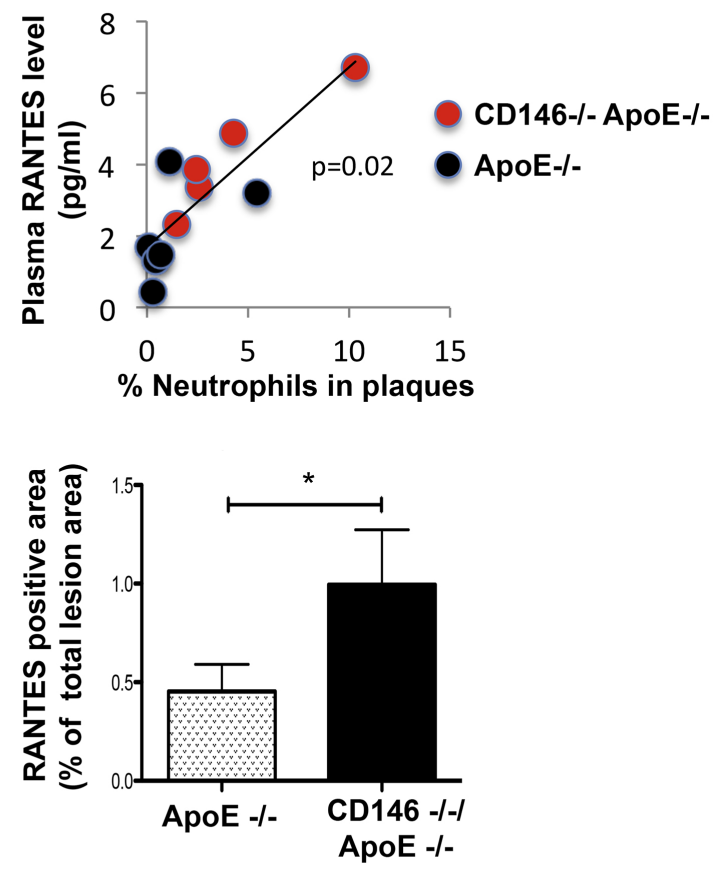
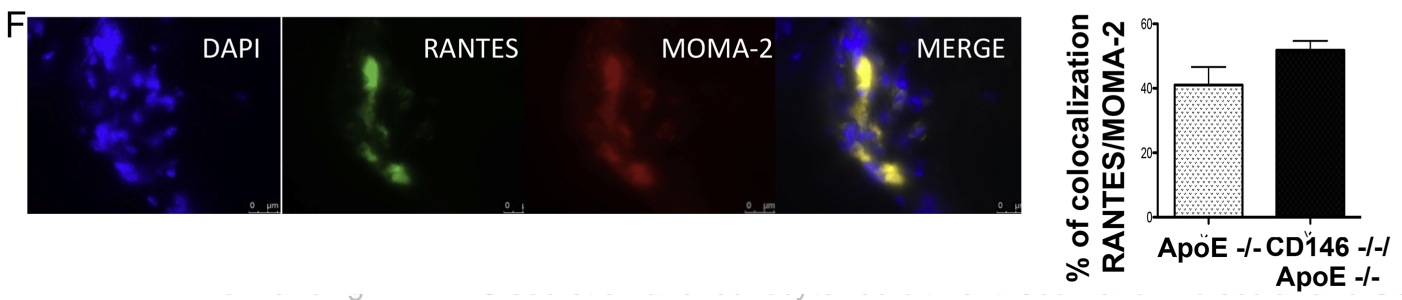
A

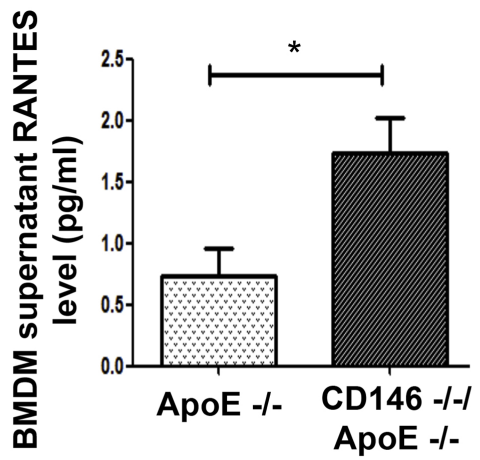

B
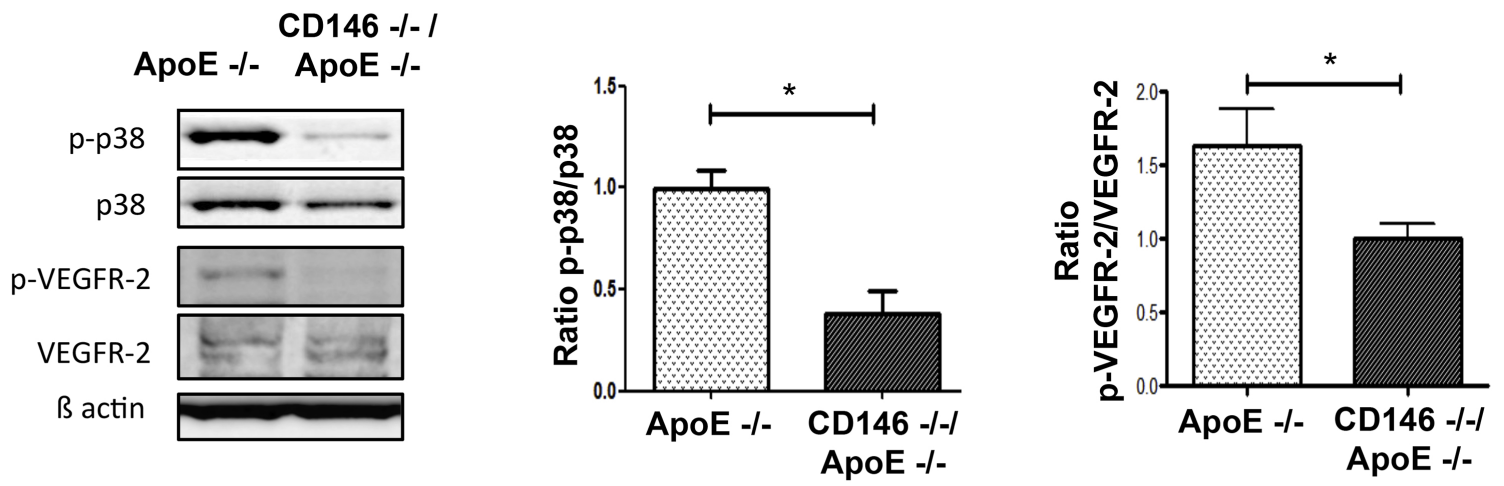

C

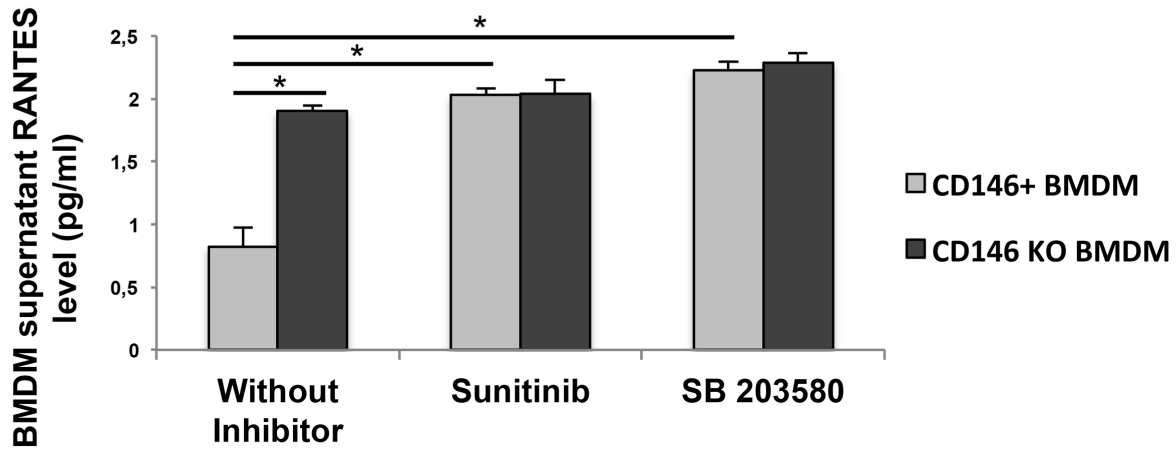

D

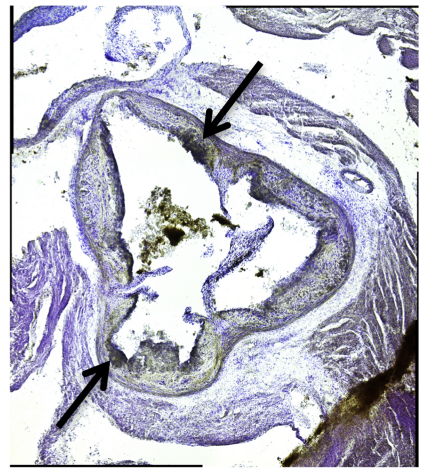

ApoE -/-

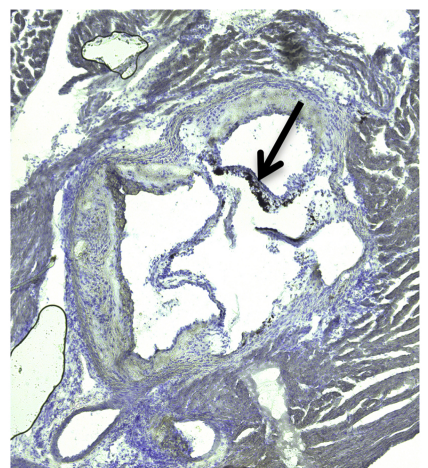

ApoE -/- CD146 -/-

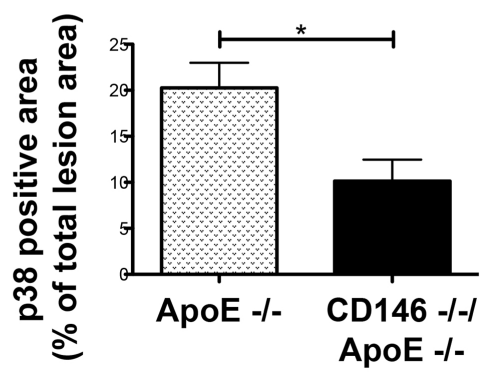

Figure 3 
Vehicle Maraviroc
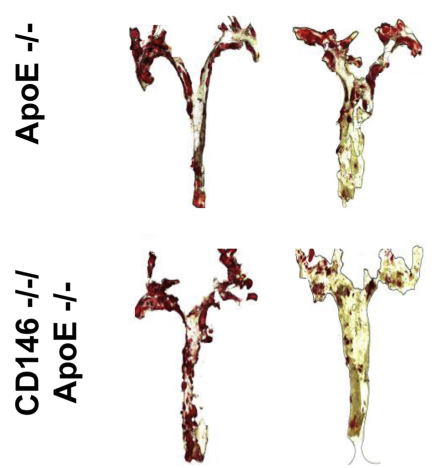

B

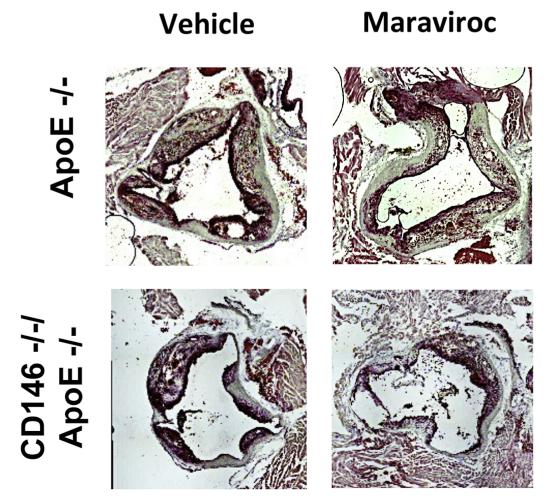

C

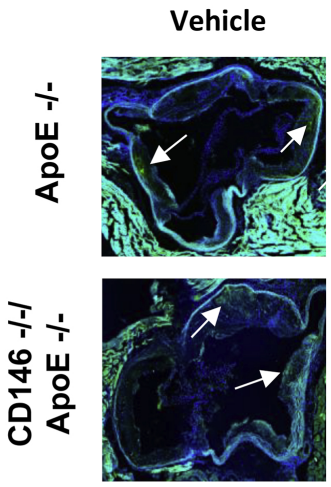

Maraviroc
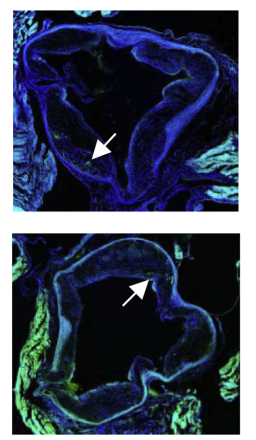

Maraviroc

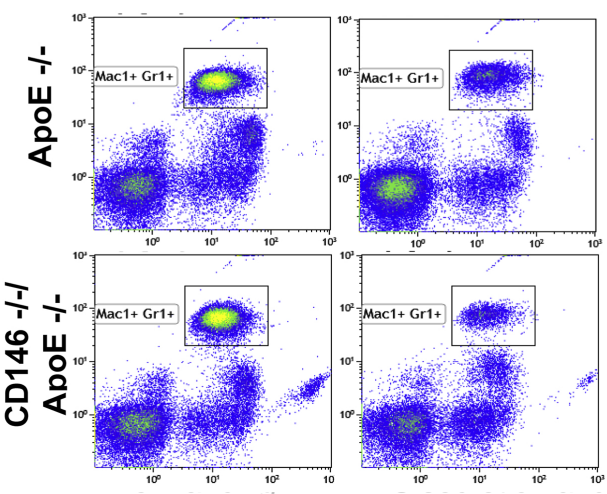

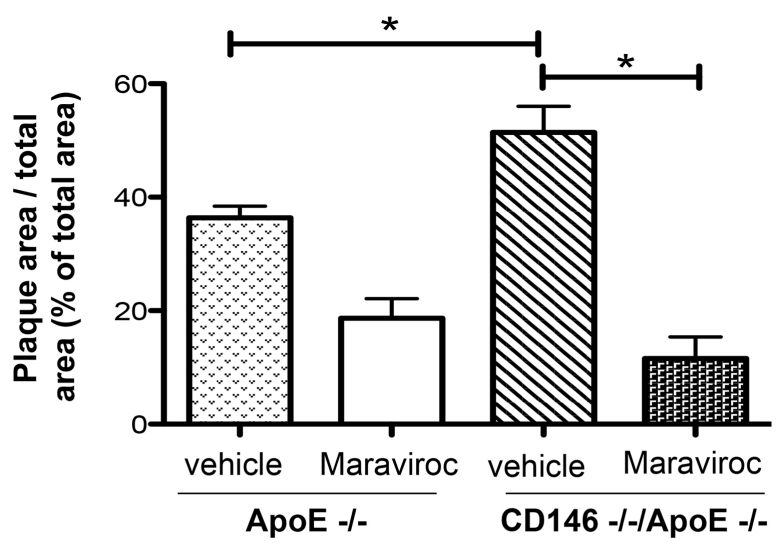
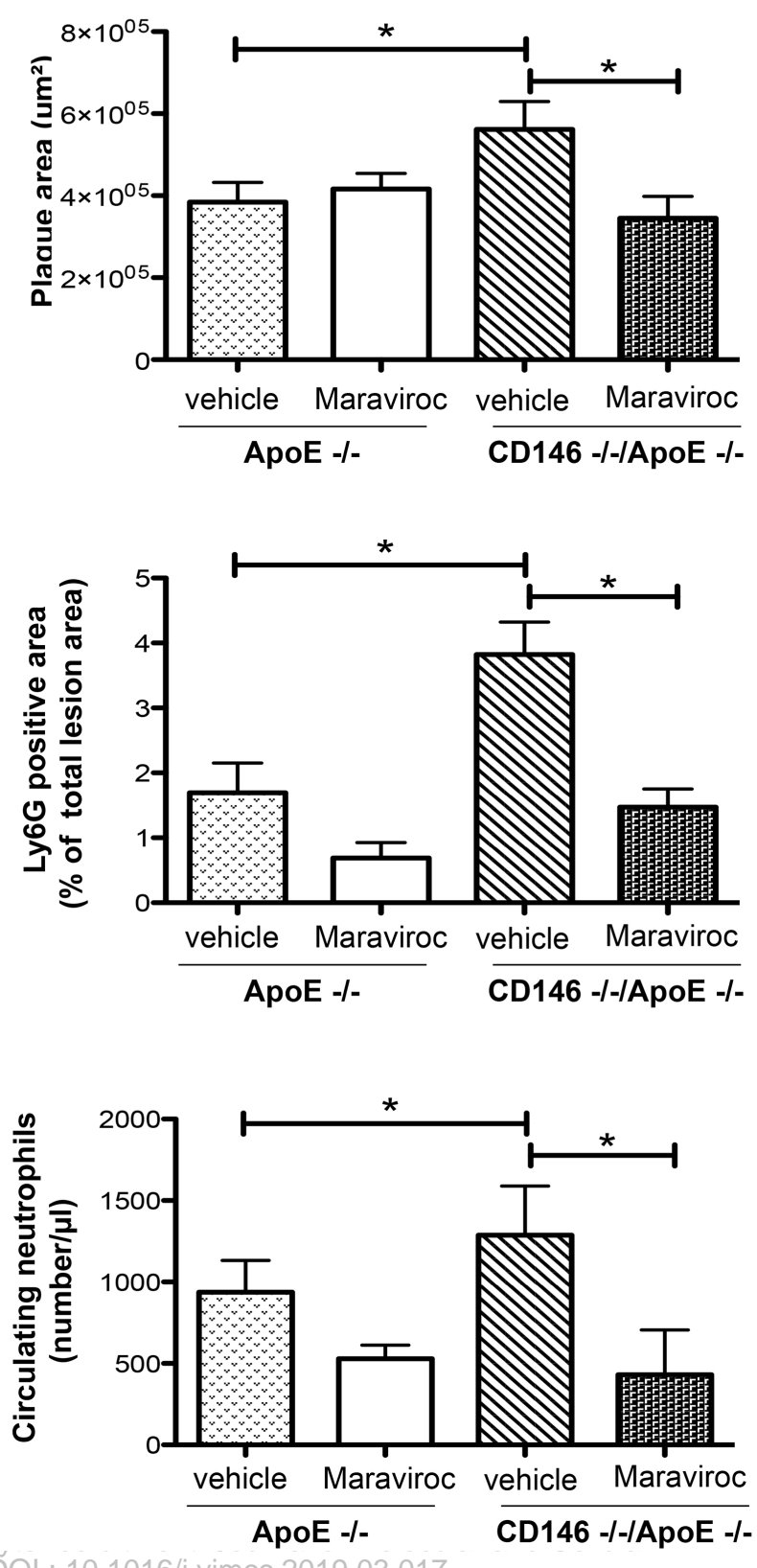